\title{
A rare ant on Samoa: first record of the cryptic subfamily Proceratiinae (Hymenoptera, Formicidae) and description of a new Proceratium Roger species
}

\author{
Cong Liu', Georg Fischer', Evan P. Economo' \\ I Okinawa Institute of Science and Technology Graduate University, Okinawa, 904-0495, Japan \\ Corresponding author: Cong Liu (cong.liu@oist.jp)
}

Academic editor: M. Ohl| Received 7 August 2015 | Accepted 6 October 2015 | Published 30 November 2015

http://zoobank.org/11C9CA39-147F-4142-AB4D-EA932E5CDE7D

Citation: Liu C, Fischer G, Economo EP (2015) A rare ant on Samoa: first record of the cryptic subfamily Proceratiinae (Hymenoptera, Formicidae) and description of a new Proceratium Roger species. Journal of Hymenoptera Research 46: 35-44. doi: 10.3897/JHR.46.5849

\begin{abstract}
In this study we present a taxonomic update for the Oceanian Proceratium. A recent ant biodiversity survey in Samoa collected an unknown Proceratium species, which we describe here as Proceratium silisili sp. n. This new species also presents the first record of this genus, as well as the whole subfamily Proceratiinae, in Samoa. Proceratium silisili is clearly distinguishable from the other Oceanian Proceratium species based on the differences in petiole node shape, number of mandible teeth, shape of the abdominal segment IV, as well as the surface sculpture on the head. A detailed description of P. silisili, high-quality specimen images, as well as an identification key to Oceanian species and a diagnostic discussion are provided.
\end{abstract}

\section{Keywords}

Oceania, Proceratium, Samoa, taxonomy, Proceratium silisili 


\section{Introduction}

Proceratium is the type genus of the Proceratiinae subfamily which also includes the genera Discothyrea Roger, Probolomyrmex Mayr, as well as the extinct Bradoponera Mayr. Within the subfamily, Proceratium represents the genus with the highest species diversity of currently 82 extant species (Discothyrea: 34, Probolomyrmex: 26 valid species; Bolton 2015). All three genera are more or less globally distributed, although comparatively patchily. Discothyrea and Probolomyrmex, however, both seem to be absent from temperate climates and most of the Nearctic and Palaearctic regions. Many species live hypogaeically, nest in soil, leaf litter, rotten wood, under deep-set stones (Brown 1958a, Baroni Urbani and de Andrade 2003, Fisher 2005), but also in tree branches (Brown 1974). Due to cryptic lifestyles and local rarity uncertainties about their biologies and biogeographic distributions are high (Baroni Urbani and deAndrade 2003, Hita Garcia et al. 2014). Specialised predatory behaviour has been documented in both Discothyrea and Proceratium. Workers were carrying and feeding on arthropod (probably spider) eggs and storing them in their nests (Brown 1958a, 1958b, 1974, 1980, Dejean and Dejean 1998, Dejean et al. 1999, Fisher 2005b, Katayama 2013).

According to Hita Garcia et al. (2014) the taxonomy of the genus is in a moderately good condition, with a relatively recent global revision by Baroni Urbani and de Andrade (2003) providing a valuable basis for smaller taxonomic updates and regional revisions (Bharti and Wachkoo 2014, Fisher 2005b, Hita Garcia et al. 2014, Hita Garcia et al. 2015, Xu 2006). For Japan Onoyama and Yoshimura (2002) provided a taxonomic revision for the genus, raising the number of Proceratium species from three to four. With increasing use of subterranean sampling techniques, more new taxa can be expected in the future. For example, due to recent intensive collection efforts on Madagascar and neighboring islands (Fisher 2005a), 11 undescribed species have been recorded for the Malagasy region (Hita Garcia and Fisher, unpublished - see www. antweb.org) - which is a large number for this relatively small genus.

In the Oceanian region, nine species are presently known, eight of them recognized by Baroni Urbani and de Andrade (2003): Proceratium austronesicum De Andrade, 2003, P. ivimka De Andrade, 2003 and P. snellingi Baroni Urbani \& de Andrade, 2003 in Papua New Guinea, P. caledonicum De Andrade, 2003 and P. politum De Andrade, 2003 in New Caledonia, P. oceanicum De Andrade, 2003 and P. relictum Mann, 1921 in Fiji, and P. papuanum Emery, 1897 in Malaysia, Indonesia, Papua New Guinea, Philippines, and the Solomon Islands. Earlier this year, Hita Garcia et al. (2015) described $P$. vinaka as a third Fijian Proceratium species (=P. sp FJ01 in Sarnat and Economo (2012)).

In the present publication, Proceratium silisili sp. n., the tenth Oceanian species, is described. It was collected on Samoa and represents the first record for both, the genus Proceratium and the subfamily Proceratiinae on these islands (Wetterer and Vargo 2003). Morphologically, it is very distinct from the other species found across the region and shows a unique combination of characters that distinguishes it from all other Oceanian Proceratium species. Thus, it seems likely that $P$. silisili sp. n. is not a 
member of the silaceum clade as defined by Baroni Urbani and de Andrade (2003). This clade currently includes all other Oceanian species (Hita Garcia et al. 2015) and 20 species with very different geographic distributions. Judging by the presence of mostly ancestral character states and an absence of real synapomorphies in the majority of species belonging to this clade (Baroni Urbani and de Andrade (2003) - see strict consensus tree, fig. 29), it is possible that the silaceum clade is not a phylogenetic unit and instead comprises several unrelated clades. The outer morphology of $P$. silisili sp. n. more closely resembles that of several Neotropical Proceratium species in the micrommatum clade - in particular with mandibles often containing less than six teeth (e.g. P. micrommatum \& P. mexicanum with 4 teeth), petiole node stoutly nodiform, not squamiform as in silaceum clade, ventral petiole process small triangular, and abdominal segment IV strongly recurved. However, since the different clades were defined on the basis of presence-absence analyses of 62 morphological characters, it seems prudent to exercise caution in equating them with true phylogenetic relationships. A phylogenetic analysis including molecular data would be the next logical step in untangling the taxonomy of this phylogenetically basal ant genus.

\section{Abbreviations of depositories}

The collection abbreviation follows Evenhuis (2015). The holotype of the new species will be deposited at the following institution:

OSAKA Osaka Museum of Natural History (OMNH), Osaka, Japan

\section{Material and methods}

The holotype of the new species was collected during an inventory of the ant fauna of Samoa in 2015 by C. Liu and E.M. Sarnat. Morphological observations and measurements were performed with a Leica M165 C stereomicroscope equipped with an orthogonal pair of micrometres at a magnification of $100 \times$. Measurements were recorded in millimetres to three decimal places and rounded to two decimal places for presentation. The measurements and indices used in this study follow Hita Garcia et al. (2014, 2015) who introduced a few new measurements and indices to Proceratium taxonomy:

EL Eye length: maximum length of eye measured in oblique lateral view.

HL Head length: maximum measurable distance from the mid-point of the anterior clypeal margin to the mid-point of the posterior margin of head, measured in full-face view. Impressions on anterior clypeal margin and posterior head margin reduce head length

HLM Head length with mandibles: maximum head length in full-face view including closed mandible 
HW Head length: Maximum head width directly behind the eyes, measured in full-face view

HFeL Hind femur length: maximum length of hind femur measured along its external face

HTiL Hind tibia length: maximum length of hind tibia measured along its external face

HBaL Hind basitarsus length: maximum length of hind basitarsus measured along its external face

LT3 Abdominal tergum III length: maximum length of abdominal tergum III (= length of segment III) in lateral view

LS4 Abdominal sternum IV length: maximum length of abdominal sternum IV following Ward (1988)

LT4 Abdominal tergum IV length: maximum length of abdominal tergum IV following Ward (1988)

PeL Petiolar length: maximum length of the petiole in dorsal view including its anterior prolongation

PeW Petiolar width: maximum width of petiole in dorsal view

SL Scape length: maximum length of scape shaft excluding basal condyle

TL Total body length: combined length of HLM + WL + PeL + LT3 + LT4

WL Weber's length: diagonal length of mesosoma in lateral view from the anterior-most point of pronotal slope (excluding neck) to posterovental margin of propodeal lamella or lobe

CI Cephalic index: $\mathrm{HW} / \mathrm{HL} \times 100$

OI Ocular index: EL $/ \mathrm{HW} \times 100$

SI Scape index: SL $/ \mathrm{HL} \times 100$

DPeI Dorsal petiole index: $\mathrm{PeW} / \mathrm{PeL} \times 100$

ASI Abdominal segment index: LT4 / LT3 × 100

IGR Gastral reflexion index: LS4 / LT4

\section{Results}

Identification key to workers of Oceanic islands Proceratium (adapted from Baroni Urbani and de Andrade (2003), not including Papua New Guinea)

$1 \quad$ Dorsal face of petiole node sub-rectangular, almost as wide as long (DPeI 128) (Fig. 1A); mandibles with 4 distinct teeth; body covered with short, dense, decumbent pilosity, longer erect or suberect hairs completely absent; abdominal segment IV strongly recurved (IGR 0.25) (Fig. 1B) (Samoa) P. silisili

- $\quad$ Dorsal face of petiole node narrow and transversally compressed, distinctly wider than long (DPeI>150) (Fig. 1C); mandibles with 6 or more teeth or denticles; longer erect or suberect hairs present in addition to short decumbent pilosity; abdominal segment IV distinctly less recurved (IGR 0.46-0.54) (Fig. 1D)....... 2 

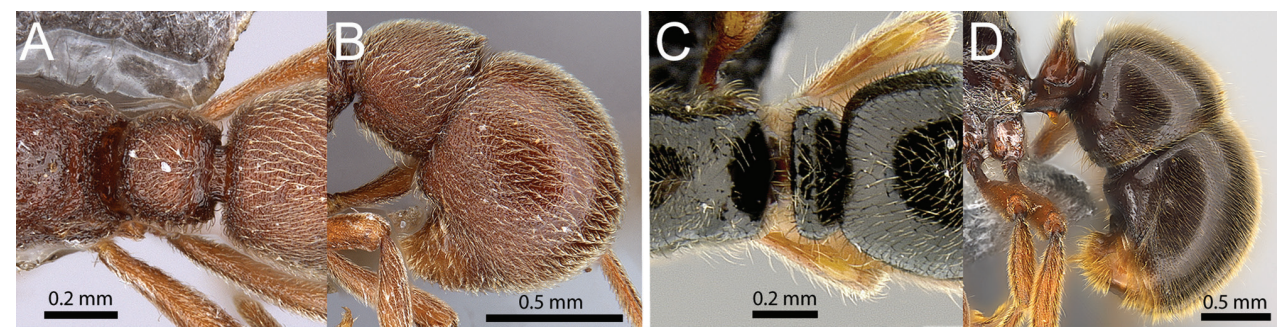

Figure I. Proceratium silisili sp. n. (CASENT0741888). A Petiole in dorsal view B Gaster in profile. Proceratium oceanicum (CASENT0171053) C Petiole in dorsal view. Proceratium relictum (CASENT0194740) D Petiole in profile.

2 Subpetiolar process reduced and rounded without any distinct projections (Fig. 2A) (Fiji) P. vinaka

- Subpetiolar process not reduced and rounded, either with spiniform or subtriangular / subrectangular lamellate projections (Fig. 2B, C, D) 3

3 Petiole shape in profile squamiform, dorsally distinctly narrower than at the base and anterior face oblique (Fig. 2B, C) .....

- $\quad$ Petiole shape in profile flattened subrectangular, at apex not distinctly narrower than at the base and anterior face vertical or subvertical (Fig. 2D) .....5 $4 \quad$ Subpetiolar process spiniform (Fiji) (Fig. 2B) P. oceanicum - Subpetiolar process lamellate, subtriangular (Fiji) (Fig. 2C) P. relictum
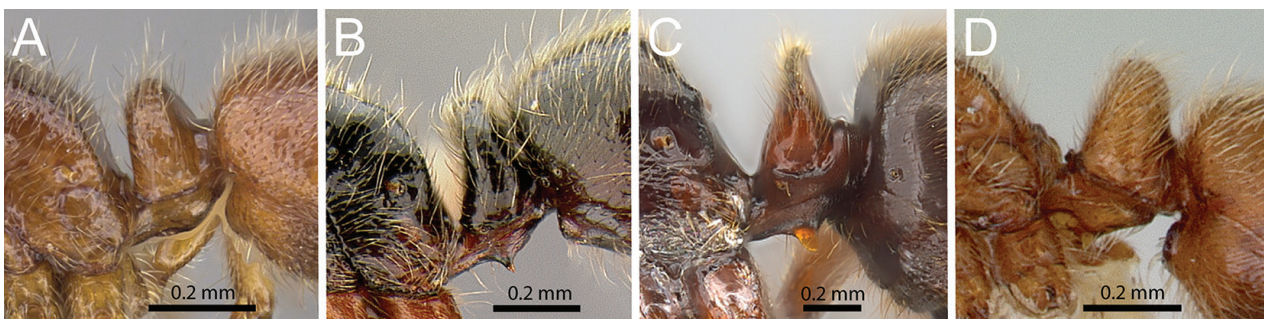

Figure 2. Petiole and subpetiolar process in profile view. A Proceratium vinaka (CASENT0187587) B Proceratium oceanicum (CASENT0171053) C Proceratium relictum (CASENT0194740) D Proceratium caledonicum (CASENT0172099).

$5 \quad$ Frontal lobes very small, each lobes' surface area covering less than clypeal area in between frontal lobes (New Caledonia) (Fig. 3A) .....P. caledonicum

- $\quad$ Frontal lobes larger than clypeal area between frontal lobes (Fig. 3B, C) ..... 6

6 Larger species (HL 0.69-0.74, WL 0.91-1.00); body smooth and shiny, head minutely punctate (New Caledonia) (Figs 3B, 4A) P. politum

- Distinctly smaller species (HL 0.55-0.60, WL 0.66-0.70); head and body weakly punctate (Fig. 3C, 4B) (Indonesia, Malaysia, Papua New Guinea, Philippines, Solomon Islands). 

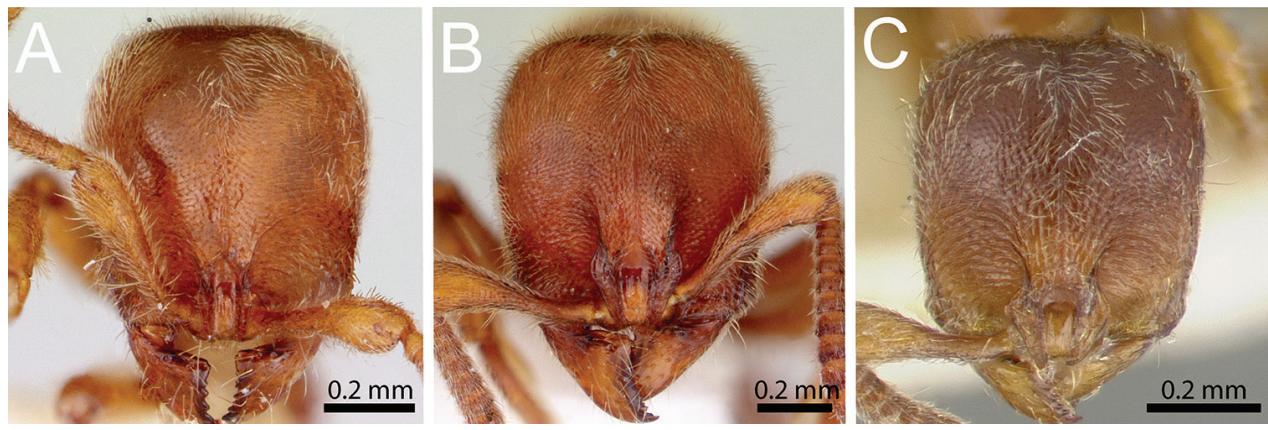

Figure 3. Head in full-face view. A Proceratium caledonicum (CASENT0172099) B Proceratium politum (CASENT0172113) C Proceratium papuanum (CASTYPE06965).
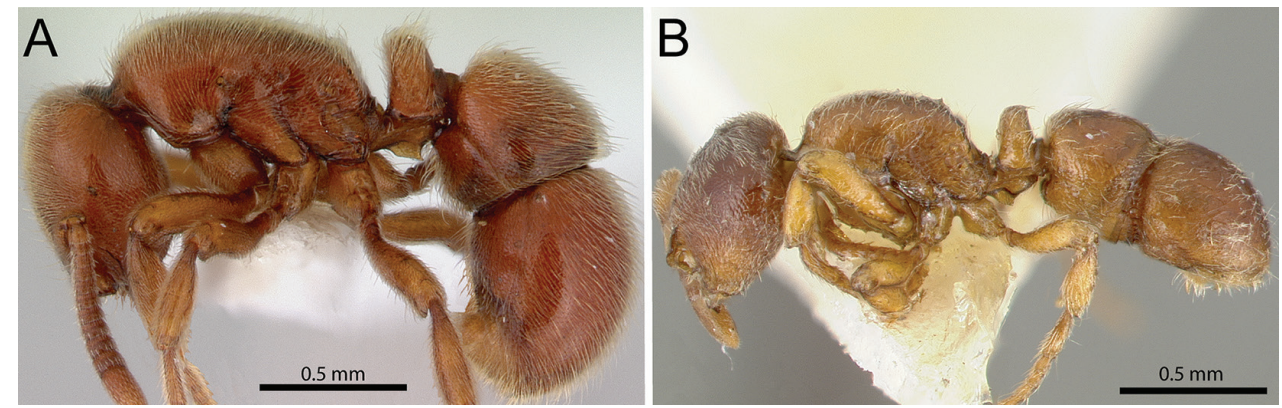

Figure 4. Body in profile view. A Proceratium politum (CASENT0172113) B Proceratium papuanum (CASTYPE06965).

\section{Proceratium silisili Liu, Fischer \& Economo, sp. n.}

http://zoobank.org/9AB0E143-16D2-4006-AEC1-F356097C9F03

Fig. 5

Type material. Holotype. Pinned worker, Samoa, Savai, 5.4km SSW A'opo vil, Mt. Silisili, 133' $10^{\prime}$ S, $172^{\circ} 30^{\prime} 23^{\prime \prime W}, 1200 \mathrm{~m}$, montane rainforest, leaf litter, 22.iv.2015 (E. Sarnat \& C. Liu) (OSAKA: CASENT0741888).

Diagnosis. Proceratium silisili differs from the other Oceanian members of Proceratium by the following combination of characters: mandible with 4 distinct teeth; petiole node in dorsal face-view subrectangular, almost as long as wide (DPeI 128); abdominal segment IV in profile view strongly recurved (IGR 0.25), highly rounded and almost spherical in its appearance; whole body very densely punctate, except for small smooth and shiny spot posterior of frontal lobes; pilosity dense, uniformly short and decumbent, long and erect or suberect hairs completely absent. Using the above character combination, $P$. silisili can also be distinguished easily from its geographically closest congeners in Fiji. Proceratium oceanicum, $P$. relictum and $P$. vinaka all have elongatetriangular mandibles with relatively long masticatory margins and more than six teeth 


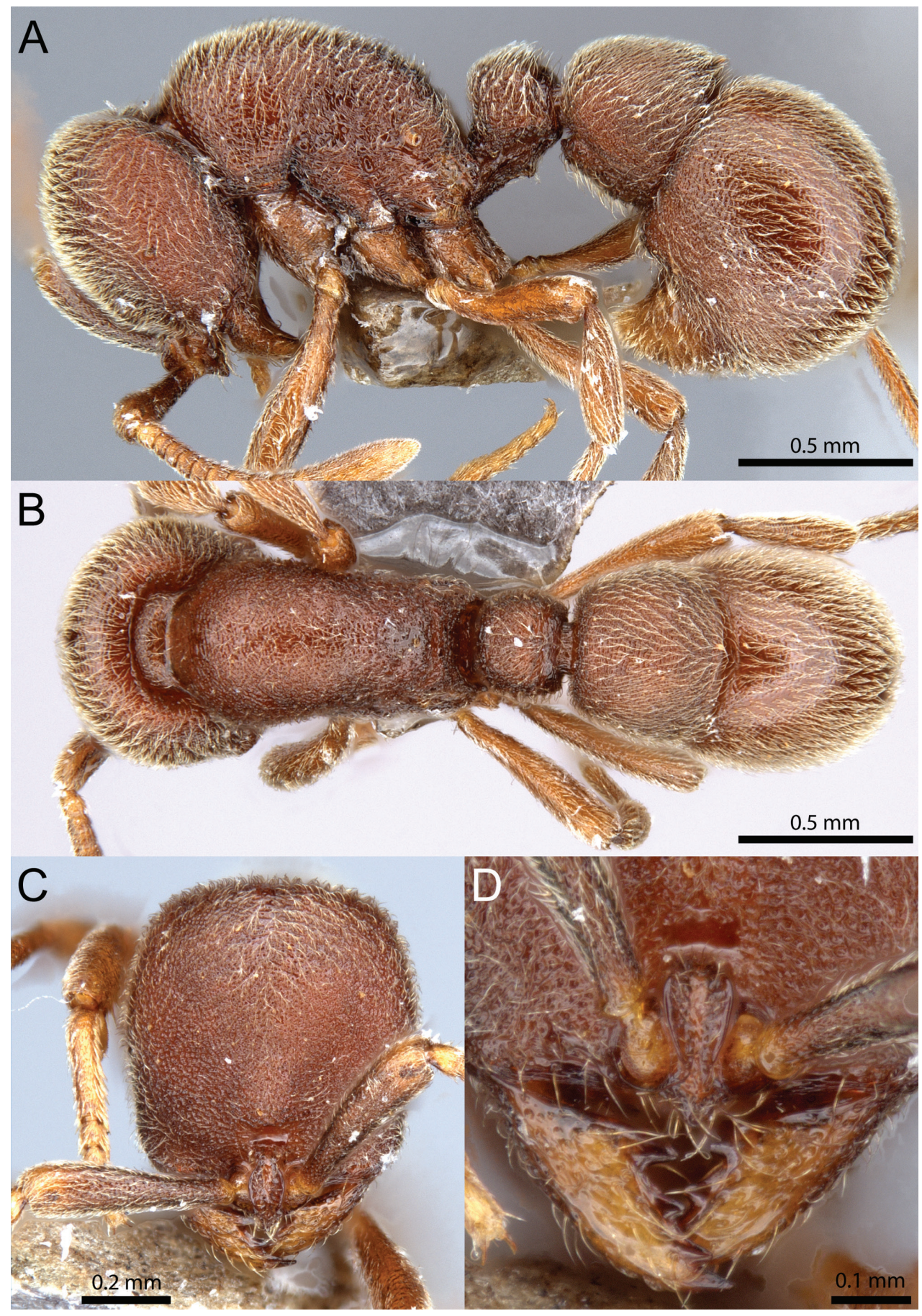

Figure 5. Proceratium silisili sp. n. (CASENT0741888). A Body in profile B Body in dorsal view C Head in full-face view D Mandible in frontal view. 
or denticles, petiole in profile either squamiform or narrow, transversally compressed subrectangular, abdominal segment IV not strongly recurved (IGR > 0.45), and long standing hairs present.

Worker measurements (N=1). TL 3.36; EL 0.04; SL 0.56; HL 0.83; HLM 0.99; HW 0.75; WL 0.97; HFeL 0.65; HTiL 0.52; HBaL 0.27; PeL 0.24; PeW 0.31; DPeL 128; LT3 0.4; LS4 0.2; LT4 0.8; OI 6; CI 90; SI 74; IGR 0.25; ASI 204.

Worker description. In full-face view, head subrectangular, longer than wide (CI 90), sides and posterior head margin convex. Mandibles with four distinct, well developed teeth, curved triangular with short masticatory margin. Clypeus strongly reduced, anteromedially with a small, triangular projection, anterolaterally reduced to extremely narrow with a thin wall in front of antennal sockets. Frontal carinae absent or vestigial, frontal lobes narrow, not covering the antennal sockets, posteriorly strongly convergent, ending just after posterior limit of antennal sockets. Eyes very small (OI 6), consisting of single ommatidium.

Mesosoma in profile convex, almost as long as maximum head length including mandibles. Lower mesopleuron with well impressed sutures, propodeum without posterior teeth, propodeal lobes small, reduced and blunt, posterior declivity relatively steep, in posterolateral and posterodorsal view separated from lateral propodeum by a distinct margin, propodeal spiracle circular and facing posterior end of mesosoma, situated slightly above mid height. Front and hind tibia with pectinate spur present, both without calcar of strigil, mesotibial spur absent, pretarsal claws simple, arolia absent. Petiole node in profile about as high as long, anterior face almost vertical, the dorsum almost flat, anteriorly and posteriorly weakly rounded, in dorsal view subrectangular with convex sides and slightly wider than long (DPeL 128), ventral process a small, blunt tooth.

Abdominal segment III in dorsal view anteriorly wider than petiole, posteriorly diverging, in profile abdominal sternite III anterolaterally with small, angulate anterior projection on either side of shallow median depression. Constriction between abdominal segments III and IV distinctly impressed. Abdominal segment IV strongly recurved (IGR 0.25), highly rounded and almost spherical in its appearance, abdominal tergum IV about twice as long as abdominal tergum III (ASI 204). Remaining abdominal segments reduced and comparatively inconspicuous, curved forwards.

Whole body in profile and in dorsal view covered with uniform dense layer of short, decumbent hairs, longer erect hairs completely absent.

Sculpture on mandibles irregularly punctate, on remainder of body very densely punctate, except for small smooth and shiny spot posterior of frontal lobes. Punctation also less strongly developed on abdominal segment IV, tergum IV appearing more shiny.

Body color dark red, legs and flagella of lighter, reddish brown coloration.

Distribution and ecology. At present, the new species is only known from Savai island in Samoa, and is likely endemic to Samoa. The type locality is a montane rainforest on Mt. Silisili, situated at an elevation of $1200 \mathrm{~m}$. Only one single worker of the new species was collected through leaf litter extraction. The genus Proceratium has not been previously reported from Samoa according to the GABI database (Guénard et 
al. in review). There is no additional information about its ecology due to the limited available material.

Taxonomic notes. The identification of $P$. silisili within the Oceanian region can be easily performed with the character combination given in the diagnosis. The new species is morphologically distinct from all the other members in the Oceanian region. It is thus possible that the Samoa species has a different origin than the other species in the region and that it is a descendent of a New World ancestor from the micrommatum clade. Several of the observed morphological characters are in support of this hypothesis: the mandibles have four teeth only, clypeus medially narrow with triangular projection, and mesotibiae without pectinate spur present. Also the subrectangular shape of the petiole and the absence of a lamellate ventral process, as well as the strongly recurved and almost spherical shape of the abdominal segment IV point in the same direction, although a triangular to strongly reduced ventral process can also be observed in the Proceratium species present on Fiji. A more definitive placement of the new species within the genus phylogeny, however, has to be postponed until more conclusive (e.g genetic) data can be analysed.

\section{Acknowledgements}

Fa'fetai lava to the Samoa government and kind people of Aopo community for allowing specimen collection and exportation. We thank Eli Sarnat for organizing and leading this ant survey. We thank Akanisi Caginitoba, Fialelei Enoka, Va'atele Anoifale Mulipola for the help with collection. We are also thankful to James Atherton for his help in the field.

We thank Michael Ohl, Marek Borowiec, and Brian Fisher for editing and reviewing the manuscript. The authors acknowledge the support of OIST and an NSF grant to EPE (NSF DEB-1145989).

\section{References}

Baroni Urbani C, de Andrade ML (2003) The ant genus Proceratium in the extant and fossil record (Hymenoptera: Formicidae). Museo Regionale di Scienze Naturali - Monografie 36: $1-480$.

Bharti H, Wachkoo A (2014) New synonymy of Proceratium williamsi Tiwari (Hymenoptera, Formicidae). ZooKeys 388: 69-72. doi: 10.3897/zookeys.388.6972

Bolton B (2015) An online catalog of the ants of the world. Available from http://antcat.org [accessed 1 August 2015]

Brown WL (1958a) Predation of arthropod eggs by the ant genera Proceratium and Discothyrea. Psyche 64: 115. doi: 10.1155/1957/45849

Brown WL (1958b) Contributions toward a reclassification of the Formicidae. II. Tribe Ectatommini (Hymenoptera). Bulletin of the Museum of Comparative Zoology 118: 173-362. 
Brown WL (1974) A remarkable new island isolate in the genus Proceratium (Hymenoptera: Formicidae). Psyche 81: 70-83. doi: 10.1155/1974/90949

Brown WL (1980) A remarkable new species of Proceratium, with dietary and other notes on the genus (Hymenoptera: Formicidae). Psyche 86: 337-346. doi: 10.1155/1979/78461

Dejean A, Dejean A (1998) How a ponerine ant acquired the most evolved mode of colony foundation. Insectes Sociaux 45: 343-346.

Dejean A, Grimal A, Malherbe MC, Suzzoni JP (1999) From specialization in spider egg predation to an original nesting mode in a "primitive" ant: a new kind of lestobiosis. Naturwissenschaften 86(3): 133-137. doi: 10.1007/s001140050585

Evenhuis NL (2015) The insect and spider collections of the world website. Available from http://hbs.bishopmuseum.org/codens [accessed 1 August 2015]

Fisher BL (2005a) A model for a global Inventory of ants: A case study in Madagascar. In: Jablonski NG (Ed.) Biodiversity: A Symposium Held on the Occasion of the $150^{\text {th }}$ Anniversary of the California Academy of Sciences June 17-18, 2003. Proceedings of the California Academy of Sciences, ser. 4 56(Suppl. 1): 78-89.

Fisher BL (2005b) A new species of Discothyrea Roger from Mauritius and a new species of Proceratium Roger from Madagascar (Hymenoptera: Formicidae). Proceedings of the California Academy of Sciences 56: 657-667.

Guénard B, Weiser M, Gomez K, Narula N, Economo EP (in review) Revealing the distribution of ants: the Global Ant Biodiversity Informatics database.

Hita Garcia F, Hawkes PG, Alpert GD (2014) Taxonomy of the ant genus Proceratium Roger (Hymenoptera, Formicidae) in the Afrotropical region with a revision of the $P$. arnoldi clade and description of four new species. ZooKeys 447: 47-86. doi: 10.3897/zookeys.447.7766

Hita Garcia F, Sarnat EM, Economo EP (2015) Revision of the ant genus Proceratium Roger (Hymenoptera, Proceratiinae) in Fiji. ZooKeys 475: 97-112. doi: 10.3897/zookeys.475.8761

Katayama M (2013) Predatory behaviours of Discothyrea kamiteta (Proceratiinae) on spider eggs. Asian Myrmecology 5: 121-124.

Onoyama K, Yoshimura M (2002) The ants of the genus Proceratium (Hymenoptera: Formicidae) in Japan. Entomological Science 5: 29-50.

Sarnat EM, Economo EP (2012) The ants of Fiji. University of California Publications in Entomology 132: 1-398.

Ward PS (1988) Mesic elements in the Western Nearctic ant fauna: taxonomic and biological notes on Amblyopone, Proceratium, and Smithistruma (Hymenoptera: Formicidae). Journal of the Kansas Entomological Society 61: 102-124.

Wetterer JK, Vargo DL (2003) Ants (Hymenoptera: Formicidae) of Samoa. Pac Sci 57: 409-419. doi: $10.1353 /$ psc. 2003.0036

$\mathrm{Xu} \mathrm{ZH}$ (2006) Three new species of the ant genera Amblyopone Erichson, 1842 and Proceratium Roger, 1863 (Hymenoptera: Formicidae) from Yunnan, China. Myrmecologische Nachrichten 8: 151-155. 